Review Article

\title{
Biodiversity Storehouses and Showcases of Sacred Natural Sites for Nature Conservation and Climate Change Mitigation
}

\author{
Mastewal Hailemariam \\ Department of Biology, Natural and Computational Science College, Debre Berhan University, Debre Berhan, Ethiopia \\ Email address: \\ mastwalhmariam@gmail.com, bir.moges.et@gmail.com
}

To cite this article:

Mastewal Hailemariam. Biodiversity Storehouses and Showcases of Sacred Natural Sites for Nature Conservation and Climate Change Mitigation. American Journal of Life Sciences. Vol. 7, No. 2, 2019, pp. 38-46. doi: 10.11648/j.ajls.20190702.11

Received: May 8, 2019; Accepted: June 4, 2019; Published: June 29, 2019

\begin{abstract}
Sacred Natural Sites (SNS) are parts of land or water that have spiritual significance for specific communities which are often hotspots of cultural, and biological diversity. Using various indigenous means, SNS provide cheap and effective protection of natural resources. It represent the world's oldest protected areas. SNS have served as important reservoirs or storehouses of biological diversity, preserving unique and/or rare plants and animal species. They tend to harbour rich in species of biodiversity, and occasionally provide more effective conservation than formal protected areas. So SNS are considered showcases for the conservation of biological and cultural diversity in nature. These lead to their role in biodiversity conservation and provide ecosystem services, conservation $\mathrm{d}$ and sources of medicinal plant, water and climate regulation, support nutrient cycling and soil formation, and cultural services like spiritual, religious and sense of place. Beyond conservation, SNS as nodes of resilience, restoration and adaptation to climate change. Moreover they are a paradigmatic example of community-based conservation that relies upon local people's understanding and involvement of natural resources. Despite the effectiveness of many community managed SNS, their values have until recently largely been ignored by conservation practitioners. Because of the increasing human activities pressure on natural resources including within them, it is a race against time to secure them before they disappear.
\end{abstract}

Keywords: Biodiversity Conservation, Climate Change, Sacred Site

\section{Introduction}

The resultant loss of biodiversity and ecosystem services has been happening and continue at an alarming scale across the world [1-3]. Natural resource conservation also challenging in vast human-modified landscapes [4]. Similarly, creating institutions for conservation and management of biodiversity and natural resources are both difficult and cost [5]. However, one alternative to building new institutions is supporting and learning from informal conservation institutions that exist like sacred natural sites $[6,7]$. These can offer crucial opportunities for biological conservation outside protected areas and it is destined to become pivotal [8]. From an institutional perspective, sacred natural sites are conserved by local communities for a host of spiritual and social values. It represent the world's oldest protected areas management systems in human history [9, 10].

Sacred Natural Sites (SNS) are portions of land or water that hold spiritual significance for specific communities [11]. SNS are often hotspots of cultural, as well as biological diversity [10]. SNS can provide cheap and effective ways of protecting natural resources using various indigenous means such as religious/cultural beliefs and taboos [12]. For example, sacred mountains, rivers, forests and groves, caves, wells and islands are still form a large and mainly unrecognized network of sanctuaries around the world [13, 14]. SNS tend to harbour high rates of biodiversity, and occasionally provide more effective conservation than formal protected areas in the same region [9]. They are often visible in the landscape as vegetation-rich ecosystems contrasting from adjoining, non-sacred or degraded environments [15]. Moreover, SNS represent ecologically and institutionally diverse libraries of 
biodiversity and ecosystem [7].

Sacred natural sites (SNS) have served as a primary conservation network for conserving nature and culture [16]. SNS are considered showcases for the conservation of biological and cultural diversity, because their strong cultural importance derives from, and requires maintenance of biodiversity $[9,10,14,17]$. SNS are socially constructed places [18], centering on natural and other man-made objects as epicenters of local ecology, community life, livelihood and belief [17]. SNS are humanity's important heritages built from time immemorial; they are manifestations of an inextricable link between human cultural systems and nature [18]; key evidences of nature as cultural archives and anthropogenic imprints [19].

Generally, widespread survival of SNS have had significant value to humans. Emphasizing sacred natural sites as a primary conservation network will lead to a better analysis and understanding of their role in conserving biodiversity, and providing ecosystem services, such as provisioning (e.g. food and medicinal plants), regulating (e.g. water and climate), supporting (nutrient cycling and soil formation) and the more obvious cultural services (e.g. spiritual, religious and sense of place) [16]. This may also allow the economic valuation of SNS based on holistic approaches to valuation that include broad measures of human well-being. SNS are as nodes of resilience, restoration and adaptation to climate change [16]. In many cases, SNS offer opportunities for building landscape connectivity networks and recovering ecologically sound because they form important refugia for biodiversity and maintain a dynamic cultural fabric in the face of global change [16].

The roles of SNS and their research interest has been increasing since the 1960s [20]. However, despite SNS are distributed worldwide, they are commonly studied in many parts of Asia and Africa but broader geographic survey work is currently incomplete [53]. Currently, their conservation significance is increasingly recognized globally $[13,21]$. But, many conservationists, developers, managers and policy-makers have gone unrecognized this primary conservation networking of SNS $[7,16]$. This has led to the decision to commission an overview of available information on the world of sacred natural sites, as one of the ways of intensifying this review work. Objectives of the review:

$\mathrm{i}$ To provide concepts and associated features of 'sacred natural site', and which informs and facilitates review.

ii To provide an overview of the various ways in which SNS play in biodiversity and natural resource conservation, and climate change mitigation drawing from perspectives from across the world.

iii To provide an overview of the related information and knowledge required to respect, protect and animate these sites.

iv To establish a simple database of the range of initiatives, approaches, organizations and networks involved in this work.

$\mathrm{v}$ To recommend who the relevant people and initiatives might be, as a basis from which to build an alliance to strengthen the overall aim of enhancing the knowledge, practices, protection and general awareness of sacred sites and associated features.

\section{Definition and Concepts of Sacred Natural Sites}

According to Websters New International Dictionary (1932), the word sacred comes from the Latin word "sacrare", meaning to consecrate, or to make holy [15]. In classical terms, sacred is set apart as holy for religious reasons, usually by religious ceremony. It is consecrated by religion, and consecrated to religious use [15]. In this paper, the term natural is used to refer to the non-built environment. 'Natural' or 'pristine wildernesses' are in fact cultural landscapes, created by humans or modified by human activities, and that traditional peoples have been the 'authors' of some in situ biodiversity. Therefore, Sacred Natural sites (SNS) defined as natural areas of special spiritual significance to peoples and communities. They include natural areas recognized as sacred by indigenous and traditional peoples, as well as natural areas recognized by institutionalized religions or faiths as places for worship and remembrance [15]. Many SNS are areas of great importance for the conservation of biodiversity [15]. In fact, very often the reasons for protecting the spiritual connections between people and the earth, and for conserving biodiversity in their lands, are inseparable [22].

The geophysical and biological characteristics of SNSs can be described as a small stone, a standing tree, or an entire mountain range, but their sacredness can only be described by the peoples who hold them sacred. Activities attached to SNSs or carried out within them are similarly diverse and dependent on local values. They are noted for providing various services including spiritual, medicinal, and material and ecological functions like degraded land restoration [11, 12].

\subsection{The Sacramental Relationship with Religion, Nature and Conservation}

Faith and nature has become a growing topic of inquiry and a promising avenue for the future of conservation [11]. Indirectly or directly, religion contribute to environmental conservation. Indirectly, it conserve by influencing the way people perceive and act towards environment and religion whereas, directly by enforcing actual protection of areas that are set apart by virtue of their symbolic or spiritual value $[9$, 23].

As a result of spiritual beliefs, many communities throughout the world have given a special status to natural sites such as mountains, rivers, lakes, caves, forest groves, coastal waters and entire islands. Many of these have been set aside as sacred places. Their sacredness reasons are diverse such as: they may be perceived as abodes of deities and ancestral spirits; as sources of healing water and plants; places of contact with the spiritual, or communication with the 'more-than-human' reality; and sites of revelation and transformation. They are sometimes temple sites, the burial 
grounds of ancestors, places of pilgrimage, or sites associated with special events. Particular plant and animal species may also be considered as sacred by some communities. While many of the sacred natural sites have historical significance, they are not static in time or space; new sites can be created in response to changing circumstances and environment [15].

SNS access is often taboo and restricted to a small circle of people, such as priests or pilgrims [15]. In Maharashtra in India, customs relating to the management of sacred groves are set down by priests with knowledge of forest deities and their influence on life. Ancient folklore and stories are told details on the supernatural penalties that will result if the groves are desecrated [15]. In some cases sacred sites provide a range of products used in rituals by traditional priests or shamans, or in healing, such as the medicinal plants used in Indian Ayurvedic medical system. In other areas, the harvesting of plants or the hunting of animals is not permitted in consecrated areas. As a consequence of their taboo status and access restrictions, many sacred places have served as important reservoirs of biological diversity, preserving unique and/or rare plants and animal species [15]. From a more theoretical angle, the presence of a symbolic link between spiritual beliefs and the environment confirms the global prominence of "intangible" values of nature as fundamental and effective drivers of conservation and as the possible ultimate source of a conservationist ethos [8].

The sacredness and natural areas link has rightly been deemed to offer crucial opportunities. SNS form a shadow conservation network at the applied level [9] that can integrate and complement existing protected areas (PAs) by conserving habitats and species not represented in official conservation schemes and improving connectivity in agricultural landscapes [24]. Besides being coherent with an integrated view of socio-ecological systems, therefore, SNS seem to particularly fit rising paradigms of biological conservation for at least two additional reasons: (1) they confirm the effectiveness and resilience of local drivers and forms of knowledge in bringing about effective conservation; and, in doing so, (2) they offer a somewhat more democratic view of conservation practice, being grounded on emic understandings and valuations, rather than on the top-down imposition of an exogenous set of values [8]. Moreover, SNS are a paradigmatic example of community-based conservation that relies upon local people's understanding and involvement [8].

\subsection{SNS Support for Biological Diversity, Conservation and Ecosystem Services}

SNS have remnant nature and high level of protection, which means they often have a particularly rich biodiversity. SNS are often rich in species diversity, being sometimes more diverse than even protected areas or forest reserves [54]. For example, Ethiopian Orthodox Church surveys of a small sample of 28 church forests revealed a stunning 168 woody species including 160 indigenous to the country [25]. These church forests also harbor vast insect biodiversity [26], provide pollination and hydrological services for nearby farmland [27], and serve as seed banks for native plants [28].
Many churches and forests also have 'area closures' in order to improve water tables and habitat, environmental rehabilitation, food security, heath, conflict and peace building, refugees and education. Other land protected by belief systems are found in Ethiopia include: Muslim, Oromo Gedda, Ghdeio and Sidama community [29].

In some areas SNS are valuable genetic reservoirs, and can be useful indicator sites. They are also useful sources of genetic material that can be used for rehabilitating degraded environments. Afforestation schemes that included the establishment of fodder banks for livestock and the planting of cash crops on the periphery of sacred groves have also helped to enlarge the sacred groves through an additional buffer zone around the holy site [15]. SNS also serve as key refugia for plant and animal species [30], increasing water filtration, reducing soil erosion, and providing an array of other ecosystem services [31].

Many sacred natural sites contribute to the conservation of biodiversity. Local people frequently protected sacred sites more carefully than official protected areas. The small size of many sacred sites often limits biodiversity as compared with larger areas of natural habitat, both in overall abundance and in the range of species supported [15]. SNS vary in size, biodiversity value and tenurial status. In some cases, sacred sites are very small areas found on private land. In other cases, traditional peoples view whole landscapes as sacred, and it is difficult to identify self-contained sites. Taken alone, the significance of smaller sites may be quite limited for biodiversity conservation, but taken together they can represent sizeable protected areas [15].

Traditional peoples are usually attempting to benefit from the protection and goodwill afforded by the deity in return for not disturbing the sanctity of the sacred area, rather than explicitly managing resources for conservation goals. Secondly, sacred natural sites also clearly express the interdependence of both ecological and cultural heritage. However, caution should be exercised in linking biodiversity, indigenous knowledge and cultural preservation in ways that imply a kind of 'enforced primitivism' [15]. There can also be problems with attempting to validate and integrate traditional ecological knowledge within conservation programmes. Such knowledge is not static and frozen in time, but depends on material conditions, responds to changing environments, and the uses to which it is put [15].

SNS represent a clear exemplification of similar views on biocultural diversity and "humans as part of ecosystems". [23] (2011), found a strong association between religious plurality and high biodiversity rates in so-called hotspot countries [33]. However, [10] and [34], have stressed the explicit role of SNS as hotspots of biocultural diversity, given their contribution to the conservation both of biological values and traditional cultural customs [8]. The cultural practices and biodiversity inextricable linkage can concretely be seen in some of the floristic patterns often encountered at SNS [8, 35]. These suggest that the sites in question do not necessarily represent patches of untouched nature, although that might occasionally be the case, but are the outcome of active management 
regimes that result beneficial rather than detrimental to local diversity [8].

SNS harbour important plants and animals [36]. Valuable plants and other ecosystem services partly found in SNS [9]. Similarly, sacred groves protect several crop wild relatives [37], provide people with other ecosystem services such as acting as windbreaks and provision of water sources to local villages [9], played an important role in peoples' livelihoods [38]. They also contain certain species that perform key functions in nutrient conservation and could play an important role in the rehabilitation of the surrounding degraded landscapes [54]. The role of remnant sacred forests in forest rehabilitation has also been recognized [39].

Comparable densities of sacred natural sites are found in the few African countries where detailed surveys have taken place. In Tanzania there are over 600 sacred groves, in Ghana over 2,000 sacred forests, in India over 100,000; and in Japan Shinto and Buddhist shrine forests cover over 110,000 hectares [9, 10]. In Ethiopia there are more than 35,000 Orthodox churches [40]. The majority of the churches and monasteries have protected areas of old forests that are rich in biodiversity. No detailed information exists regarding these sites, however a conservative estimate is that $80 \%$ of churches each have protected forest areas of at least 1 hectare. Therefore conservative estimated total church forests total 28,000 hectares ([29]). With new high-resolution satellite imagery revealing more than 8,000 church forests ranging from $<1$ hectare to over 100 hectares distributed across the Amhara Region [7].

\subsection{Soil and Water Conservation}

Sacred groves play an important role in soil and water conservation. They improve the soil stability of the region and act as soil binder [12]. Plants are maintained to bind the soil thereby preventing soil erosion. They can therefore play a very important part in land restoration programmes by preventing or minimizing erosion through their shading effect and provide an atmosphere conducive for both macro- and micro-organisms that help in nutrient cycling, resulting in improved soil fertility. They are also noted for improving soil fertility and preventing surface runoff and thereby reducing soil erosion [12].

Water of different rivers are treated as holy among all sources and used in all rituals and worships [12]. Important sources of water such as rivers, ponds and streams which can serve as sources of drinking water for both humans and animals can be found in sacred groves $[37,12]$. In other areas, sacred sites may play a role in safeguarding critical sites in watersheds, or helping to preserve the ecological integrity of entire landscapes $[15,41]$.

\subsection{Role of SNS for Harvesting and Conservation of Traditional Medicine}

Ethnobotanical knowledge is a fundamental repository of the material and intangible values that local people have attributed to elements of biodiversity. This knowledge is often related to spiritual practices and religious sites, where useful plants have been nurtured and conserved [8]. The medical uses of sacred groves have been recorded on many occasions in the world [9]. Both important ecological traits including endemic, rare, and threatened species and traditional customs have often found a refuge and space of preservation at sacred sites [9] [8]. SNS also represent important examples of the application of traditional ecological knowledge [8], and indigenous ethnobiology. Among the biodiversity patterns recorded in sacred groves and other sacred landscapes, high densities of medicinal plants and other useful species are not uncommon, confirming that these places have been managed by local communities as repositories of vital resources and knowledge [8]. Rich ethnobotanical knowledge is also well rooted in the area, and is locally correlated with its high floristic diversity [42].

Medicinal plants are at the center of the growing pluralism of medicine in our contemporary world [43, 44]. The role SNS play in the conservation of plant biodiversity of medicinal importance (medicinal plants) also is an important dimension of this growing area of research. The increasing endangerment of medicinal plants on the one hand and the role SNS and other informal protection areas, especially in the developing world, play in their conservation, on the other, are also getting attention of researchers and policy makers [44, 45]. Globally, emerging studies generally show that SNS play positive roles in the conservation of plants, including medicinal ones [46]

SNS such as sacred groves are important sources for harvesting medicinal plants for sustaining traditional medical practices, which in turn sustains local ways of selective conservation of medicinal plants. In Ethiopia, with 80 per cent of the population dependent on traditional medicine, local communities turn to existing sacred forest areas to harvest medicinal plants. For many of the so-called mysterious and difficult-to-manage health problems, medicinal plants are more likely to be harvested from wild areas, including sacred forests, while for simple, common health problems plants in backyards often serve this need [3].

Across communities in Ethiopia, as is the case in Sidama, sacred forests serve as good sources for households to select and harvest herbs, climbers and other small plants that are not easily found elsewhere. Broadly speaking, the community sees their sacred forests as important havens for hundreds of plants, from the humblest hayso (common grass or herb) to the graceful dagucho ( $P$. falcatus). In view of this, it is perhaps understandable that Wonsho-Sidama sacred forests are repositories for the preservation of medicinal plants [3].

\subsection{Sacred Natural Sites as a Model of Conservation Institution}

Sacred forests represent a unique stroke of good fortune for the conservation community, but without support for continued management of indigenous biodiversity this luck may not hold. Curbing the global biodiversity crisis will require learning from any and all successful conservation institutions, including traditional and religious institutions [47]. Sacred sites in the midst of human-dominated 
agroecosystems in low-income countries can have a particularly profound impact on conservation outcomes, as much of the remaining land in biodiversity-rich areas is used by rural farmers and pastoralists.

The full potential benefits from the ecological and institutional diversity of sacred natural sites can only be realized through:

i Enhancing efforts to catalogue and monitor sacred natural sites to ensure biodiversity and institutional knowledge are not lost;

ii Studying the institutional structures of sacred forest systems, learning from past forest conservation successes and identifying how ancient institutions adapt to modern challenges and changing incentives;

iii Promoting ongoing stewardship through active consideration of sacred natural sites in national and international policies, including exploring options for payments for ecosystem services (PES) to church communities.

The Friends on Gamo Gofa Sacred Sites Association in Ethiopia demonstrates how SNSs can support cultural and biodiversity conservation. After forest lands were converted to agriculture, local people vowed to protect their sacred places. Ritual festivals fostered respect for the area's cultural history, decreasing pressure on the Gamo sacred forests. The custodians of the sacred sites (the elders) were accorded legal authority, helping them better protect both their culture and biodiversity [48].

Thus in addition to their immediate ecological conservation value, sacred sites such as Ethiopian church forests are also examples of powerful social institutions that have ensured the provision of cultural and ecological ecosystem services for generations. The enduring strengths and recent transformations of these institutions can thus offer invaluable lessons for conservation policy [7].

In Ethiopia, the Ethiopian Orthodox Tewahido Church is one of the oldest Christian churches in Africa and has a long history of protecting and preserving indigenous forest as sanctuaries for prayer and burial grounds for church followers. In a general sense the forests surrounding churches are seen as sacred, with the trees symbolic of angels guarding the church [25]. However at the community-level each church operates largely autonomously, with each having developed its own contextually-defined approach to forest management [7]. In some cases church forest governance has involved the construction of walls clearly demarcating forest boundaries [49]. In other areas the church pays guards to patrol forests to detect and punish trespassers (with punishments varying across churches - from public apologies before the community to arrest by police for more serious infractions). In still other communities some extractive uses of church forests are permitted - such as harvesting wild fruits, honey, or fuelwood from dead church forest trees. At times even harvesting live trees is allowed - typically for church building construction or repair, or (even more rarely) for sale of indigenous timber to neighboring churches [50].

From a strict conservation perspective many such extractive forest uses cannot be sustained. But from an institutional perspective the diverse uses of church forests, often strictly conservationist but sometimes more utilitarian, is a key part of how indigenous trees have been conserved in Ethiopian Orthodox church forests while natural forest has all but disappeared elsewhere. In other words, the thousands of church forests across the Northern Highlands can be understood not only as precious islands of biodiversity and in need of preservation, but also as invaluable experiments in "what works" for protected areas management in Ethiopia across a variety of social, economic and environmental contexts [7].

\section{Role of Sacred Natural Sites for Climate Change Mitigation and Adaptation}

Sacred natural sites as nodes of resilience, restoration and adaptation to climate change offer opportunities for recovering ecologically sound, local ways of life [16]. The widespread survival of sacred natural sites amongst many cultures indicates that these sites have had significant value to humans. Those that survived were adaptable and had custodians whose cultural beliefs enabled them to adapt to the changing conditions under which they lived. Hence the traditional cultures which have survived until the present deserve our highest respect, and modern societies may have important lessons to learn from them. Sacred natural sites can be considered nodes of resilience, or even resistance, to global change. In many cases, sacred natural sites offer opportunities for building landscape connectivity networks because they form important refugia for biodiversity and maintain a dynamic cultural fabric in the face of global change ([16]). They are remnants of variety, heterogeneity and multi-functionality in increasingly simplified homogeneous landscapes, and it is increasingly recognized that diverse biological and cultural systems are more resilient and adaptable than homogeneous systems [33].

Sacred natural sites and their associated communities have demonstrated themselves to be remarkably resilient to change, however, the scale of these changes is now taking its toll. Today, global change is a term increasingly used to describe processes in human society and the environment characterized in terms of uncertainties [14]. Changes such as biodiversity loss, environmental degradation, human population increase, shortages of resources, imbalances in wealth and poverty, increasing cultural homogenization and modernity all contribute to impacts on sacred natural sites. Deriving from and linked to these is global climate change, which is escalating uncertainty and is noticeable at a number of sacred natural sites. Increasing numbers of extreme droughts, floods and hurricanes and other extreme weather events constitute existential challenges to many societies. The links between human behaviour and environmental change are complex and the effects of these links on biological and cultural diversity are in many cases unpredictable [16]. 
Dudley et al., (2010) confirm that the remaining sacred natural sites often contain high biodiversity values, creating opportunities for landscape connectivity and the creation of corridors between conservation areas which are much needed in the face of climate change and economic growth [9]. In the rapidly developing response to climate change, sacred natural sites need to be taken fully into account. They can make substantial contributions to climate change mitigation and adaptation, but there are dangers that inappropriate policies, for example in forestry, could inflict further damage. Increased research and understanding on the roles of sacred natural sites in biological and social resilience are needed and these need to be translated into effective policies ([16]).

\section{Conservation Challenges of Sacred Natural Sites}

Despite the effectiveness of many community managed sacred natural sites, their values have until recently largely been ignored by conservation practitioners [9]. Many sacred natural sites have been incorporated into government protected areas, suggesting implicit recognition of their conservation values but often without also recognizing their traditional custodians. Lack of recognition of sacred natural sites is partly due to a lack of understanding amongst conservationists, and in some cases due to traditional custodians maintaining secrecy as a form of protection or even a tenet of their faith, hence rendering the sites invisible to the eyes of outsiders. Fortunately, this oversight is now being reversed and the potential conservation role of sacred natural sites is increasingly acknowledged. However because of the increasing pressure on natural resources, often including within sacred natural sites, it is a race against time to secure them before they disappear [9].

Rapid economic development and the changes in lifestyle accompanied by it are alienating people more and more from nature and ancient cultural heritage. Such trends have considerably reduced people's awareness of the non-material values of the landscape. Ancient sacred sites are becoming increasingly damaged, and in some areas they have become the most endangered cultural and natural monuments. In general, evidence suggests that sacred natural sites have been well protected in the past [51]. The potential of sacred sites in conservation of species and ecosystem services has been reiterated in many of the papers cited earlier in the world. However, increased pressures on resources and changing social norms and belief systems are undermining many sacred sites that have survived for hundreds of years [9]. The rapid degradation and loss of sacred natural sites severely threatens valuable biodiversity, ecosystem services, cultural resources and even ways of life [16].

Despite their multiple values sacred natural sites are being lost in many parts of the world [16]. Key causes include:

$i$ destruction due to land-use change and conversion promoted by government economic policies;

ii damage and deterioration from insensitive nature conservation and archaeological policies and practices;

iii erosion due to cultural change, modernity and broad 'progressive' development contexts;

iv damage and sometimes destruction from religious absorption, adoption, competition and impositions;

$\mathrm{v}$ pressures from population increase, resources shortages and material poverty.

The needs of local communities for new sources of income and developing their tourism industries have already incorporated many remarkable sites into development activities. As a result of developers' lack of awareness, ill-considered tourism has often had a devastating effect on the natural and cultural heritage of sacred sites. Custodians who are connected to such sites via indigenous culture and historic religious traditions have either disappeared or been crowded out.

But in spite of their ecological and spiritual benefits, due to a combination of economic, environmental, and cultural factors the integrity of church forests like many other sacred natural sites has continued to decline in Ethiopia. For example, the sacred church and monastery lands of the Ethiopian Orthodox Church have survived for many centuries as islands of natural forest biodiversity in a sea of deforested landscape across much of the Ethiopian highlands [7]. For many interesting reasons related to the spiritual values attached to the churches, monasteries and their sacred lands, these biodiversity islands have survived the general pressure for timber and fuelwood gathering that has degraded the surrounding landscape. However, the biodiversity of some of these churchyard forests is currently being depleted as a result of continued deforestation of the surrounding areas for fuelwood and timber [7].

Church forests are decreasing in both size and density, with visible losses in biodiversity due to livestock grazing, fuelwood harvesting and other pressures [25]. Grazing in particular causes irreversible damage through consumption and trampling of seedlings, soil compaction and erosion [40]. Moreover, as small forest fragments are degraded, biodiversity suffers even further from physical edge effects such as light intensity, wind and temperature variability, and reduced soil moisture and humidity [28]- feedback loops that will likely become even more severe with climate change [52].

Finally, with rising populations and rising incomes some communities have actively cleared forest to construct church buildings or expand burial sites - traditional practices that now exceed forests' regenerative capacity. Shifts in economic incentives and cultural norms have led other communities to plant cash crop trees such as Eucalyptus spp. in church forests rather than the traditional nurturing of indigenous seedlings, leaving forests even more impoverished in terms of floristic diversity [50]. The dwindling biodiversity of sacred natural sites has begun to attract international attention ([10], and some ecologists now advocate prioritization of sacred natural sites for preservation. The IUCN has published a guide for protected area managers on the subject of sacred natural sites [11]. And in Ethiopia some conservation institutions are directly funding stone wall construction around church forests 
to protect ecologically valuable sites [49].

\section{Conclusion and Further Recommendations}

Natural sacred sites are sources of spiritual living force for communities and nations and a store of biodiversity for regions. They are hotspots of biological and cultural diversity. The face of ongoing biodiversity losses can offer through SNS which are crucial opportunities for conservation. SNS tend to harbour high rates of biodiversity, and more effective conservation than protected areas. SNS can integrate and complement existing protected areas (PAs) by conserving habitats and species not represented in official conservation schemes and improving connectivity in agricultural landscapes. SNS are also often repositories of the oldest part of the cultural heritage of mankind, and the part that is closest to nature, and at the same time are nature conservation areas of indigenous people.

SNS often contain high biodiversity values, creating opportunities for landscape connectivity and the creation of corridors between conservation areas which are much needed in the face of climate change and economic growth. In the rapidly developing response to climate change, sacred natural sites need to be taken fully into account. They can make substantial contributions to climate change mitigation and adaptation.

Although research and guidance has been undertaken to support the integration of sacred natural sites in conservation planning and management further conservation is needed in a number of areas as many sacred natural sites has continued to decline and threatened in the world. The rapid degradation and loss of sacred natural sites severely threatens critical biodiversity, ecosystem services, cultural resources and even ways of life. Based on this the following recommendations for actions that should be initiated immediately:

i Stakeholders and concerned body build a global coalition to protect sacred natural sites and publicize their values to both people and nature.

ii A coherent and effective strategy should be developed for the conservation of sacred natural sites.

iii Based on the right of self-determination, indigenous peoples should be empowered to protect and manage their sacred natural sites

iv Greater public awareness and incorporate need to be develop in conservation and education programmes in the concept of the sacred in nature that is found in all religions and indigenous spiritualties.

$\mathrm{v}$ Particular attention should be given to sacred natural sites as part of the adaptive response to global changes in climate, economics, governance, communications, education, health and human well-being.

vi Funding agencies should be encouraged of all types to support the conservation and management of sacred natural sites.

vii National and local governments should be develop guidance for to take into account sacred natural sites in their policies, legal instruments and planning mechanisms. viiiPrivate sector like tourism, agriculture, forestry, industries need to develop and expand guidance and codes of conduct to better protect sacred natural sites in their business models, social responsibility programmes, planning mechanisms and field operations.

ix Increase research and understanding on the roles of sacred natural sites in biological and social resilience are needed and these need to be translated into effective policies.

\section{References}

[1] Díaz, S., Reyers, B., Bergendorff, T. et al. (2012). Biodiversity and ecosystems for a planet under pressure. Rio +20 Policy Brief \#4, Planet under Pressure: New Knowledge towards Solutions.

[2] Watson, J., Dudley, N., Segan, D., Hockings, M. (2014). The performance and potential of protected areas. Nature, 515, 67-73.

[3] Doda, Z. D. (2017). Sacred natural sites, herbal medicine, medicinal plants and their conservation in Sidama, Ethiopia. Cogent Food \& Agriculture 3: 1365399.

[4] UNEP-WCMC. (2014). World Database on Protected Areas. Web. http://www.unep-wcmc.org

[5] McCarthy, D., Donald, P., Scharlemann, J. et al. (2012). Financial costs of meeting global biodiversity conservation targets: current spending and unmet needs. Science, 338, 946-49.

[6] Ostrom, E. (2009). A general framework for analyzing sustainability of social-ecological systems. Science, 325, 419-22.

[7] Reynolds, T., Shimekach, T. and Wassie, A. (2015). Sacred natural sites provide ecological libraries for landscape restoration and institutional models for biodiversity conservation. GSDR 2015 Brief.

[8] Fabrizio, F. (2013). Sacred sites for the conservation of biodiversity. 2013, University of Zurich, Faculty of Science. URL: https://doi.org/10.5167/uzh-93306

[9] Dudley, N., Bhagwat, S., Higgins-Zogib, L., Lassen, B., Verschuuren, B., Wild, R., 2010. Conservation of biodiversity in sacred natural sites in Asia and Africa: a review of the scientific literature. In Verschuuren, B., Wild, R., McNeeley, J., Oviedo, G. (Eds.), Sacred Natural Sites: Conserving Nature and Culture. Earthscan, London, pp. 19-32.

[10] Verschuuren, B. (2010). Sacred natural sites: Conserving nature and culture. Retrieved from https://www.academia.edu/5990541/

Sacred_Natural_Sites_Conserving_Nature_and_Culture

[11] Wild, R and McLeod, C., (2008). Sacred natural sites: guidelines for protected area managers. IUCNUNESCO. Best Practice Guideline 16. IUCN Gland.

[12] Poreku G (2014). Sacred groves and biodiversity conservation in the Tolon District, Northern Region, Ghana. United Nations University Land Restoration Training Programme Swamy, P. S. 
[13] Mallarach, J.-M., and Papayannis, T. (2009). The sacred dimension of protected areas: Proceedings of the second workshop of the Delos initiative, Ouranoupolis 2007. Gland: World Conservation Union.

[14] McIvor, A., Fincke, A., \& Oviedo, G. (2008, October 6). Biocultural diversity and indigenous people's journey. Barcelona. Retrieved https://cmsdata.iucn.org/downloads/bcd_ip_report_low_res.pdf

[15] Oviedo, G., Jeanrenaud, S., and Otegui, M. (2005). Protecting Sacred Natural Sites of Indigenous and Traditional Peoples: an IUCN Perspective. Gland, Switzerland.

[16] Wild, R., Verschuuren, B. and McNeely, J. (2010). Conclusions: Sustaining Sacred Natural Sites to Conserve Nature and Culture Pp 281-291.

[17] Sponsel, L. E. (2013). Human impact on biodiversity, overview. In S. A. Levin (Ed.), Encyclopedia of biodiversity (2nd ed., pp. 137-152). Waltham: Academic.

[18] Balée, W. (2006). The research program of historical ecology. Annual Review of Anthropology, 35, 75-98.

[19] Schaaf, T. (2003): 'Environmental Conservation based on Sacred Sites'. In UNEP (1999): op.cit.

[20] Pilgrim, S., Pretty, J., Adams, B., Berkes, F., de Athayde, S. F., Dudley, N., Hunn, E., et al. (2009). The Intersections of Biological Diversity and Cultural Diversity: Towards Integration. Conservation and Society, 7, 100.

[21] Sponsel, L. E. (2008). Spiritual ecology, sacred places, and biodiversity conservation. Retrieved from https://www.eoearth.org/view/article/51 cbeecf7896bb431f69a $6 \mathrm{f} 4$

[22] Sobrevila, C. (2008). The role of indigenous peoples in biodiversity conservation the natural but often forgotten partners. The World Bank. Retrieved from https://siteresources.worldbank.org/INTBIODIVERSITY/Res ources

[23] Oviedo, G. (2001): 'Notes on the Panel's Presentations and Discussions'. Symposium on the Importance of the Protection of Sacred Natural Sites (SNS) for the Conservation of Biodiversity. Mexico City, June 12, 2001. WWF International, Gland, Switzerland.

[24] Bhagwat, S., Ormsby, A. A., and Rutte, C. (2011). The role of religion in linking conservation and development: challenges and opportunities. Journal for the Study of Religion, Nature and Culture 5 (1): 39-60.

[25] Bhagwat, S., Kushalappa, C. G., Williams, P. H., and Brown, N D. (2005). A landscape approach to biodiversity conservation of sacred groves in the Wesern Ghats of India. Conservation Biology 19 (6): 1853-1862.

[26] Wassie, A., Sterck, F., Bongers, F. (2010). Species and structural diversity of church forests in a fragmented Ethiopian Highland landscape. Journal of Vegetation Science, 21 (5), 938-48.

[27] Ermilov, S., Winchester, N., Lowman, M., Wassie, A. (2012). Two new species of oribatid mites (Acari: Oribatida) from Ethiopia, including a key to species of Pilobatella. Systematic \& Applied Acarology. 17 (3), 301-17.

[28] Lowman, M. (2011). Finding sanctuary: saving the biodiversity of Ethiopia, one church forest at a time. The Explorers Journal, 26-31.

[29] Aerts, R., Van Overtveld, K., Haile, M., et al. (2006). Species composition and diversity of small Afromontane forest fragments in northern Ethiopia. Plant Ecology, 187, 127-42.

[30] Young, J. (2012). Ethiopian Protected Areas a 'Snapshot': A Reference Guide for Future Strategic Planning and Project Funding, March 2012.

[31] Mgumia, F., Oba, G. (2003). Potential role of sacred groves in biodiversity conservation in Tanzania. Environmental Conservation, 30, 259-65.

[32] Bodin Ö., Tengö M., Norman A., et al. (2006). The value of small size: loss of forest patches and ecological thresholds in southern Madagascar. Ecological Applications, 16, 440-51.

[33] Myers, N., Mittermeier, N. A., Mittermeier, C. G., da Fonseca, G. A. B., Kent, J., (2000). Biodiversity hotspots for conservation priorities. Nature 403: 853-858.

[34] Pungetti, G., Oviedo, G., Hooke, D. (Eds.), (2012). Sacred Species and Sites: Advances in Biocultural Conservation. Cambridge University Press, Cambridge.

[35] Mesfin, F., Demissew, S., Teklehaymanot, T., (2009). An ethnobotanical study of medicinal plants in Wonago Woreda, SNNPR, Ethiopia. Journal of Ethnobiology and Ethnomedicine 5: 28 .

[36] Bhagwat S., Rutte C. (2006). Sacred groves: potential for biodiversity management. Frontiers in Ecology and the Environment, 4, 519-24.

[37] Swamy, P. S., Kumar, M. and Sundarapandian, S. M. (2003). Spirituality and ecology of sacred groves in Tamil Nadu', Unasylva, vol 54, pp 53-58.

[38] Wadley, R. L. and Colfer, C. J. P. (2004). 'Sacred forest, hunting, and conservation in West Kalimantan, Indonesia', Human Ecology, vol 32, pp 313-338.

[39] Miehe, G., Miehe, S., Koch, K. and Will, M. (2003). Sacred forests of Tibet: Using Geographical Information Systems for forest rehabilitation, Mountain Research and Development, vol 23, pp 324-328.

[40] Wassie, A., Sterck, F., Teketay, D., \& Bongers, F. (2009). Effects of livestock exclusion on tree regeneration in church forests of Ethiopia. Forest Ecology and Management, 257 (3), 765-72.

[41] UNESCO (2000): 'Culture-Based Environmental Conservation for Sustainable Development'. UNESCO Draft Project Document.

[42] Idolo, M., Motti, R., Mazzoleni, S., (2010). Ethnobotanical and phytomedicinal knowledge in a long-history protected area, the Abruzzo, Lazio and Molise National Park (Italian Apennines). Journal of Ethnopharmacology 127: 379-395.

[43] Geissler, P. W., \& Prince, R. J. (2010). Persons, plants and relations: Treating childhood illness in a Western Kenyan Village. In E. Hsu \& S. Harris (Eds.), Plants, health and healing on the interface of ethnobotany and medical anthropology. New York, NY: Beghahn Books.

[44] Salick, J., Amend, A., Anderson, D., Hoffmeister, K., Gunn, B., \& Zhendong, F. (2007). Tibetan sacred sites conserve old growth trees and cover in the eastern Himalayas. Biodiversity and Conservation, 16, 693-706. 
[45] Cunningham, A. B. (2001). Applied ethnobotany: People, wild plant use and conservation. London: Routledge.

[46] Anderson, D. M., Salick, J., Moseley, R. K., \& Xiaokun, O. (2005). Conserving the sacred medicine mountains: A vegetation analysis of Tibetan sacred sites in Northwest Yunnan. Biodiversity and Conservation, 14, 3065-3091.

[47] Carrière, S., Rodary, E., Méral, P., et al. (2013). Rio+ 20, biodiversity marginalized. Conservation Letters, 6 (1), 6-11.

[48] Maffi, L and Woodley, E, (2010). Biocultural Diversity Conservation. London, Earthscan.

[49] TREE. (2014). Tree Research Exploration and Education (TREE) Foundation. Web. http://treefoundation.org

[50] Bongers, F., Wassie, A., Steck, F., et al. (2006). Ecological restoration and church forests in northern Ethiopia. Journal of the Drylands, 1 (1), 35-44.
[51] Byers, B. A., Cunliffe, R. and Hudak, A. T. (2001). Linking the conservation of culture and nature: a case study of sacred forests in Zimbabwe, Human Ecology, vol 29, no 2, pp 187218.

[52] Cardelús, C., Scull, P., Hair, J. et al. (2013). A preliminary assessment of Ethiopian sacred groves at the landscape and ecosystem scales. Diversity, 5 (2), 320-34.

[53] Dudley, N., Bhagwat, S., Higgins-Zogib, L., Lassen, B., Verschuuren, B. and Wild, W. (2014). Conservation of Biodiversity in Sacred Natural Sites in Asia and Africa: A Review of the Scientific Literature. https://www.researchgate.net/publication/249387637

[54] Dudley, N., Higgins-Zogib, L., \& Mansourian, S. (2009). The links between protected areas, faiths, and sacred natural sites. Conservation Biology, 23, 568-577. 